\title{
El código disciplinar de la historia escolar en España: Algunas ideas para la explicación de la sociogénesis de una materia de enseñanza
}

\author{
Raimundo Cuesta \\ Fedicaria-Salamanca, España
}

\section{RESUMEN}

En este artículo se pretende dar razón de la potencialidad heurística del concepto código disciplinar aplicado al estudio de la sociogénesis de la enseñanza de la Historia en Espańa. Entendido como una tradición social inventada, el código disciplinar de la Historia tiene su momento constituyente a mediados del siglo XIX, y sus notas más características (arcaísmo, nacionalismo, elitismo y memorismo) perviven durante el modo de educación tradicional-elitista (que en España llega hasta los años sesenta del siglo XX), siendo sometido a una revisión, más discursiva que real, con motivo de la reformas educativas de 1970 y 1990, ya en plena vigencia del modo de educación tecnocrático de masas. Esta persistencia de las formas tradicionales de enseñanza en períodos reformistas se ve hoy todavía más reafirmada por una política educativa conservadora, que persigue un mayor control curricular mediante el retorno al viejo canon del código disciplinar.

Descriptores: Historia; enseñanza; España; codigo disciplinar.

\section{ABSTRACT}

This paper explains the heuristic potential of the concept of disciplinary code, when applied to the study of the sociological origins of History teaching in Spain. The disciplinary code of History as a subject - seen as an invented social tradition - began in the middle of the nineteenth century. Its main features-archaism, nationalism, elitism and rote learning-survived during the period of traditional-elitist education model, which lasted in Spain until the I960s. It went through a revision process, more apparent than real, under the education reforms of 1970 and 1990, a period in which the technocratic mass education model prevailed. Traditional teaching styles continued while reforms were being implemented. They prevail with even greater strength today, reaffirmed by conservative education policies, which aim at a tighter control over the curriculum, by returning to the old norms of the disciplinary code.

Key words: history; teaching; Spain; disciplinary code. 
RÉSUMÉ

Dans cet article on essaie d'expliquer le concept code disciplinaire en tant qu'outil puissant, du point de vue heuristique, pour étudier la sociogenèse de l'enseignement de l'Histoire en Espagne. On définit le code disciplinaire comme une tradition sociale inventée au milieu du XIXe. siècle dont les caractéristiques les plus importantes (arcaïsme, nationalisme, élitisme et culte de la mémoire) survivent pendant l'époque du mode d'éducation traditionnelle-élitiste (qui, en Espagne, se prolonge jusqu'aux années soixante du XXième siècle). Ce n'est qu'à partir des réformes de l'éducation des années 1970 à 1990 , lorsque le mode d'éducation technocratique des masses est déjà en vigueur, que l'on percevra un renouvellement, pas réel, dans le discours du code disciplinaire. Cette persistance des formes traditionnelles de l'enseignement de l'Histoire s'affermit, de plus en plus, à cause d'une politique éducative conservatrice, qui prétend un contrôle croissant des programmes scolaires au moyen du retour au vieux canon du code disciplinaire..

Mots clefs: histoire; enseignement; Espagne; code disciplinaire.

\section{Introducción}

$\mathrm{E}_{\mathrm{d}}^{\mathrm{s}}$ ESTUDIO DE LAS DISCIPLINAS ESCOLARES, pieza clave para una recomposición del "mosaico curricular" de la escuela de la era del capitalismo, es todavía, a pesar de los innegables avances conseguidos desde la década de los ochenta, una aspiración no consumada, que requiere de una investigación más detallada y de una perspectiva comparativa más amplia. La sociogénesis de las materias de enseńanza resulta una faceta insoslayable para la comprensión de las razones sociales e históricas que intervienen en la construcción del conocimiento escolar y en la difusión de los hábitos culturales hegémonicos. ${ }^{1}$

Las primeras constataciones que se infieren de un enfoque sociohistórico de las disciplinas escolares evocan la durabilidad de estos "artefactos sociales" (Goodson, 1995) y su originalidad (Chervel, I99I). Durabilidad que obliga al investigador, si realmente quiere comprender y explicar el significado profundo del saber escolar, a internarse en los tiempos largos y adoptar, en consecuencia, una perspectiva sinóptica, esto es, una visión capaz simultáneamente de abarcar el conjunto sin apartar la mirada de lo principal. Y originalidad que lleva ineluctablemente a no confundir las disciplinas escolares con un simple epifenómeno de las ciencias académicas de referencia. Por ello la historia social de las disciplinas escolares no puede concebirse ni como un subproducto o rama colateral de la historia de la ciencia y de las ideas científicas, ni tampoco como un simple vestigio de universos ideológicos observables a través de los libros de texto $\mathrm{u}$ otros documentos, tal como ha venido siendo moneda corriente en los iniciales trabajos efectuados en Espańa y otros países. Por más que los textos visibles (los manuales y programas escolares) nos ayuden a entender la recepción de las ideas científicas (el desfase, por ejemplo, entre historiografía y enseńanza) o nos faculten para explorar algunas ideologías dominantes (por ejemplo, el nacionalismo), el esclarecimiento de la sociogénesis de la Historia (o de cualquier disciplina escolar) precisa de otros marcos teóricos más complejos y de unas fuentes más variadas y sutiles, que, en consecuencia, formulen y resuelvan problemas de diferente naturaleza.

Las disciplinas escolares constituyen conjuntos culturales originales que pugnan por ocupar, con diversos apoyos y estrategias sociales, nichos curriculares en donde asentarse y petrificarse en tradiciones discursivas y prácticas. Son, en efecto, construcciones 
sociohistóricas, esto es, tradiciones sociales inventadas históricamente, que forman parte esencial del conocimiento escolar y que, por sus rasgos peculiares, propenden a perdurar en forma de estereotipos de pensamiento y de acción.

Asimismo, las materias de enseñanza, en tanto que entidades históricas portadoras de funciones sociales implícitas y explícitas, contienen dispositivos de coacción y poder, de violencia simbólica y física, evocados por el propio vocablo "disciplina". Se comportan como saberes-poderes, como campos de conocimiento "cuyos cuerpos visibles no están constituidos por el discurso teórico o científico..., sino por la práctica cotidiana y reglamentada" (Foucault, I992, p. 425). Lo que me lleva a reclamar una indagación de la Historia como materia de enseñanza superadora de la casi exclusiva atención a las dimensiones discursivas y jurídicas del conocimiento escolar, tal como viene haciendo últimamente la renovación metodológica (del marco teórico y de las fuentes) acaecida en la historia social del curriculum.

A tal fin y para descifrar la enorme complejidad de la génesis y evolución de la enseñanza de la Historia desde su fundación como materia escolar en España, he dado en utilizar un instrumento heurístico que denomino código disciplinar. Se puede definir como el conjunto de ideas, valores, suposiciones, reglamentaciones y rutinas prácticas (de carácter expreso o tácito) que orientan la práctica profesional de los docentes. En suma, el elenco de ideas, discursos y modos de hacer determinantes de la enseñanza de la Historia dentro del marco escolar.

El código disciplinar de la Historia se configura como parte integrante de la cultura escolar, y plasma una larga y duradera tradición social que cobija los discursos, los contenidos y las prácticas de la educación histórica; es un producto social que, a su vez, produce realidades socioculturales específicas. Su uso nos proporciona una aproximación más rica y distinta (por los problemas que se plantean y las fuentes que se utilizan) a la realidad sociohistórica (teórica y práctica) de la enseñanza de la Historia en el tiempo largo. De ahí que la sociogénesis del código disciplinar permite comprender, con categorías explicativas de nuevo cuño, la genealogía de usos de la educación histórica en España, dando razón de las causas que explican la secuencia y la cadencia de su evolución y, por tanto, desentrañando el significado de las continuidades y cambios habidos desde la constitución de la Historia como disciplina escolar hasta el presente. Veamos algunos de los grandes trazos de esa sociogénesis.

\section{Evolución y rasgos del código disciplinar de la Historia: fundación y pervivencia de una tradición social}

A fin de explicar el trayecto del código disciplinar de la Historia hemos establecido, reelaborando las aportaciones de C. Lerena (1976), dos grandes momentos en la evolución del sistema educativo en Espańa: el modo de educación tradicional-elitista (desde mediados del siglo XIX hasta los ańos sesenta del siglo XX) y el modo de educación tecnocrático de masas. Ambos se conciben, asimismo, como fases evolutivas del desarrollo del capitalismo y como distintas formas o modelos de producción, reproducción y 
legitimación del conocimiento escolar, es decir, como sucesivas tipologías de racionalidad socioeducativa, lógica y sociológicamente vinculadas a la esfera de la cultura y al resto de los niveles de la totalidad social.

El esquema temporal nos proporciona una primera visión panorámica de las grandes etapas de la génesis del código disciplinar. El momento inaugural y constituyente de la Historia como asignatura escolar, pues hasta entonces no había sido más que une discipline introuvable (Bruter, I997), coincide con la erección, a mediados del siglo XIX, del sistema educativo liberal. Allí el nuevo edificio de la educación histórica se levanta sobre el basamento de tradiciones discursivas y prácticas largamente sedimentadas en épocas anteriores. Posteriormente, se puede percibir una tercer momento de afianzamiento y pervivencia (lo que no excluye también la existencia de cambios) del código disciplinar fundado en los orígenes del modo de educación tradicional-elista; esta larga fase dura desde el último cuarto del siglo XIX hasta la década de los sesenta del siglo $\mathrm{XX}$, y va a ser seguida de un último periodo de reformulación del código disciplinar, en el que, ya en el seno de la nueva pauta impuesta por el modo de educación tecnocrático de masas, y dentro de un marco de constantes reformas educativas (entre 1970 y 1990), la pugna entre la continuidad y el cambio se resuelve de manera muy desigual según atendamos a las dimensiones discursivas o prácticas de la educación histórica.

Por tanto, la "invención” del código disciplinar acontece en plena revolución burguesa. Es una operación de aburguesamiento de una larga y polimorfa tradición anterior, constituida por los primigenios usos de la educación histórica desde la Antigüedad hasta el Antiguo Régimen. Ahí yacen los retazos arqueológicos de una educación histórica que lentamente va descendiendo de los palacios a las aulas. En efecto, concebida como ornato y disciplina en el adiestramiento de príncipes y los vástagos de otros estratos de las clases dirigentes, la poca Historia que circulaba en los intersticios de los limitadísimos espacios escolares del Antiguo Régimen, permanece estrechamente adherida a la matriz literaria de la que había nacido. Retórica, elocuencia y arte de la memoria; esta es la herencia de la paleohistoria escolar, a la que se suma la moderna invención jesuítica del colegio, nuevo orden del espacio y el tiempo para el sometimiento de cuerpos y almas.

La construcción de la Historia escolar puede explicarse como un parsimonioso desprendimiento y una progresiva diferenciación disciplinar del cultivo de las bellas letras y del estudio de los autores latinos, eje sobre el que giró el universo cultural de la educación de elites. Ya desde el siglo XVIII se aprecia, en los textos y contextos escolares, una tímida tendencia a la autonomía disciplinar que se materializa en la confección de los primeros manuales escolares. Por ejemplo, el Compendio de historia de España escrito por el padre Duchesne, jesuita francés al servicio de Felipe V, para la educación de los hijos de monarca, es traducido al castellano por el también jesuita padre Isla en I754 (no es mera coincidencia su condición de jesuitas, pues esta Orden forjó y difundió un prístino acervo de educación histórica), llegándose a convertir en uno de los libros de texto más empleados en el sistema escolar del siglo XIX hasta el punto de acuñar un arquetipo para la manualística posterior.

Pero el descendimiento de Clío desde las estancias palaciegas de la era del precapitalismo a las aulas del modo de educación tradicional-elitista fue, en un principio, balbu- 
ciente e inseguro, condición de todo saber a la búsqueda de reconocimiento. Todavía en el Informe Quintana de I8I3 se menciona a la Historia entre "aquellos estudios que sirven para el arte de escribir”, y sólo a partir de los años treinta, y muy especialmente con el Plan Pidal de I845, la Historia asegura una presencia independiente e irreversible en el sistema educativo. Pero esta conquista de territorio curricular en los planes de estudio fue muy incompleta en la educación primaria (sólo se generaliza legalmente, aunque no realmente, la impartición de Historia en I90I), muy débil y tardía en la universitaria (hasta la reforma de 1900 no se produce una auténtica diversificación y especialización profesional) y más continuada y segura en la segunda enseñanza (siempre desde entonces habrá historia en la multitud de planes que atraviesan este tipo de enseñanza). A pesar de este lugar modesto, la Historia, a diferencia de otras materias objeto de reiterada polémica entre "antiguos" y "modernos", una vez asentada en una parcela del espacio escolar, no tuvo que hacer frente a intereses contrarios a su presencia y disfrutó de una cierta estabilidad curricular durante todo el modo de educación tradicional-elitista.

Fue en los institutos de segunda enseñanza, obra emblemática del liberalismo decimonónico, que practicaban un tipo de educación no muy diferente de la universitaria, donde Clío encontró más tempranamente tranquilo acomodo; en sus recintos, que daban cobijo a una minoritaria y selecta grey de colegiales, se escenificó, a mediados de siglo, la invención de la Historia escolar. En efecto, entre el Plan Pidal de 1845 y la Ley Moyano de 1857 acontece la fase más intensamente constituyente del código disciplinar. Es entonces cuando "todo era preciso crearlo" (Gil de Zárate, I855, II, 62): desde los programas hasta los profesores pasando por los centros.

Pero nos equivocaríamos gravemente si pensáramos que la constitución de la Historia escolar fue un acto de pura transferencia de un saber ya hecho (la historiografía como ciencia) a un espacio escolar en formación. Nada hay de ello. La historiografía de la época se encontraba en una fase preprofesional, y por lo tanto la Historia escolar se instituye antes de que existiera tal comunidad historiográfica, al tiempo que se configura la propia historiografía como ciencia y profesión. Es más, una cierta especialización profesional como profesor de Historia (y de Geografía), en el caso de los catedráticos de instituto, se presenta como anterior a la figura de historiador profesional vinculado a la docencia universitaria. Y es precisamente de ese cuerpo de docentes, cuyas primeras oposiciones datan de los años inmediatamente posteriores al Plan Pidal, de donde principalmente emergen los discursos y los actos que forjan el código disciplinar de la Historia.

Pues bien, libros de texto, programas y cuestionarios de estudios y de acceso por oposición a los cuerpos docentes, reglamentos donde se estipulan los usos del tiempo y el espacio y donde se fijan las competencias de profesor y alumno, usos de la educación histórica a través de las rutinas cotidianas y dentro de un contexto de cultura examinatoria, etc., han de ser improvisados a partir de lo existente: una magmática y difusa creación historiográfica (filosofante, literaria y, muy frecuentemente, de importación) y unos retazos pedagógicos de educación histórica heredados del Antiguo Régimen. Sobre esa realidad proteica y muy inestable se levanta el código disciplinar, es decir, se moldea una tradición social de educación histórica llamada a tener una larga vigencia. 
Si, como es el caso, tuviera que resumir, y por tanto simplificar, los rasgos más sobresalientes que resultan de este proceso constituyente, se podría decir que los discursos y prácticas propios del código disciplinar se alimentan de las siguientes notas distintivas: arcaísmo, nacionalismo, elitismo y memorismo. El arcaísmo figura sobre todo en los niveles discursivos más explícitos del código disciplinar, es decir, en lo que denominamos los "textos visibles" de la educación histórica (libros de texto y programas oficiales), y no expresa más que una prolongación de la hegemonía cultural e ideológica del moderantismo, bajo cuya égida se efectuaron los grandes cambios educativos de mediados de siglo, que tejieron un largo matrimonio de conveniencia entre religión y liberalismo. De ahí que, por ejemplo, los temas históricos de los libros y programas decimonónicos alberguen, siguiendo la tópica vereda ciceroniana de la magistra vitae, una función educativa de la Historia de tipo moralizante. En ellos se sustituyen las categorías explicativas por rancios moldes morales convirtiendo el pasado en un campo de batalla donde pugnaban en singular combate el vicio y la virtud. Ya Durkheim (1982, p. 313) vino a señalar que la apropiación de la cultura clásica por la enseñanza jesuítica residía en una petrificación ahistórica del pasado en las virtudes o defectos de sus personajes más notables. Algo parecido sucede en los libros de texto que inventan el código disciplinar. Allí la religión y sus derivaciones moralizantes se imponen, en general, al rigor historiográfico o crítico. Es decir, impera un molde conservador de fuerte tinte religioso, donde no existe obstáculo en fundir, dentro de un esquema cronológico que sigue el "dogma de la continuidad histórica" (Citron, 1989, p. I70) bajo la forma del arbitario cultural de las edades (antigua, media y moderna), el vetusto providencialismo con la más flamante idea de progreso. Y así, concebida la Historia como "la narración ordenada de hechos verdaderos y memorables acaecidos bajo la dirección de la Providencia” (Sánchez Casado, I873, p. 5), es frecuente también, en los primeros textos escolares, iniciar la historia universal de esta guisa: "unos cuatro mil años antes del nacimiento de nuestro señor Jesucristo, Dios creó el mundo..." (Verdejo Páez, I846, p. I).

El segundo rasgo que da significado a la Historia escolar desde su fundación, muy vinculado al anterior, es una obsesiva nacionalización del pasado, que se transparenta en el discurso historiográfico y escolar como una predominante apología del trono y del altar bajo el tenue manto protector de un liberalismo ecléctico. Nacionalización legendaria que corre paralela a la verificada por la incipiente historiografía de la época, que tiene en Modesto Lafuente a su más preclaro representante. Religión y patria es la siempre renovada cantinela que impregna la historiografía y la historia escolar de la fase constituyente del código disciplinar y que, como larga tradición social, se perpetúa, con todos los matices que se quieran, durante el modo de educación tradicional-elitista, tal como se puede comprobar, por ejemplo, en el análisis de los textos escolares decimonónicos realizado por J. García Puchol (1993) y R. López Facal (1999) o en el curriculum de primera enseńanza, entre $\mathrm{I} 890$ y 1939 , desmenuzado por $\mathrm{M}^{\mathrm{a}}$ del Mar del Pozo Andrés (2000). Otra cosa es que, como sostiene Carolyn P. Boyd (1997), las elites políticas carecieran de una interpretación común del pasado nacional, pero que ese pasado se convirtiera en materia de pugna política no autoriza a pensar que la naciona- 
lización de las conciencias dejara de estar presente en todos los grados de la enseñanza (aunque con intensidades y matices diferenciales).

Ciertamente, la reducida escolarización popular en el nivel primario y la rígida exclusión clasista y sexista del resto de los grados educativos durante la mayor parte del modo de educación tradicional-elitista puede poner en cuestión la incidencia efectiva de los textos visibles (programas y manuales) sobre la mayoría de la población. Hay, sin duda, otras vías de socialización nacionalizadora de las clases populares, que están por estudiar. Pero los límites de la acción nacionalizadora del sistema escolar residen en otro rasgo propio del código disciplinar y del conjunto del sistema educativo: el elitismo, que se muestra, sin tapujos, en toda la normativa reguladora decimonónica.

La Historia como saber escolar posee ab origine la impronta de un saber al servicio de la "distinción" de las clases dirigentes, un conocimiento que, siguiendo a Veblen, calificaríamos como propio de las clases ociosas, ostentoso, placentero y, de inmediato, poco práctico, de una utilidad diferida a los asuntos públicos. Antonio Gil de Zárate, ínclito hombre de letras y director de la trascendental reforma educativa del Plan Pidal, tildaba de vergonzoso que "los pertenecientes a las clases distinguidas de la sociedad ignoren lo que esta sociedad ha sido y cómo se ha formado." (Gil de Zárate, I855, III, p. 27I).

Esta marca de identidad social irá largamente unida a la enseñanza de la Historia en los niveles secundario y universitario. Hasta tal punto es así que hemos podido distinguir, en los textos, contextos y usos de la educación histórica en Espańa, dos tipos de enseńanza de la Historia según fueren sus destinatarios sociales: la "Historia con pedagogía" y la "Historia sin pedagogía".

En efecto, si leemos los libros de texto aprobados por la Administración y los que fueron más utilizados durante la era isabelina (I833-1868) en las escuelas primarias y en los institutos de segunda enseńanza, podemos encontrar similitudes y diferencias: sobre una base común que, con diferentes matices e intensidades, concibe la Historia como una narración de hechos verdaderos, organizados cronológicamente, de fuerte sabor moralizante y nacionalista, etc., se observan diferentes formatos, estilos, artificios e intenciones pedagógicos. La "Historia con pedagogía", cuyo paradigma podría ser el Prontuario de historia de España de Terradillos (I846), sigue y reconduce la vieja tradición del diálogo y la versificación de los primitivos manuales escolares al estilo del Duchesne-Isla y otros precedentes de la manualística protohistórica del código diciplinar, mientras que como ejemplo de la "Historia sin pedagogía", propia de la educación secundaria, podría mencionarse el Curso elemental de Historia (I847) de Rivera, que prescinde de todo aparato pedagógico explícito y da por supuesto un destinatario culto (un nińo sabio) y una ciencia ya hecha (una historia "culta") que se sirve de forma lineal y resumida.

Para algún lector de nuestra época, acostumbrado a juzgar estos asuntos con los esquemas de la rígida jerarquización de edades impuesta en el sistema escolar moderno, nada sería más natural: pedagogía para los más pequeños, ciencia para los más mayores. Pero no era una simple cuestión de edades (en los institutos se ingresaba entre los nueve y diez años); era una cuestión de clases. En efecto, si sometemos los textos escolares de las "dos historias" a la prueba de su exégesis dentro de sus contextos reales (la rudi- 
mentaria y pobre escuela-aula de primaria de las clases populares frente a los institutos de segunda enseńanza reductos de los estratos mesocráticos y de las clases dirigentes) cobran nuevos significados los usos diversos y los distintos protagonistas (profesores y alumnos) de la educación histórica.

El ideal de educación del "caballero español" del Bachillerato estaba reservado a un grupo muy reducido de la población (y sólo masculina durante mucho tiempo) y era, asimismo, encomendado a una selecta y masculina corporación docente creada al mismo tiempo que los propios institutos: los catedráticos. La educación catequística de muy escaso o inexistente contenido histórico (frecuentemente la Historia sagrada fue su sucedáneo) entregada a un subproletariado docente: el maestro. Las barreras sociales, que en muy buena porción permanecieron sin alteraciones de fondo durante todo el modo de educación tradicional-elitista, mantuvieron la separación entre las "dos historias" escolares. Así, pues, a tal clase, tal Historia.

Finalmente, otra nota distintiva del código disciplinar será el memorismo como práctica de la enseńanza y sobrentendido pedagógico duradero de las "dos historias”. Precisamente la trabajosa y difícil recomposición de los contextos escolares y la reconstrucción de la única profesión especializada en la enseñanza de la Historia (la de los catedráticos), autoriza decir que la presencia de Clío en las aulas del nuevo sistema escolar decimonónico se efectuó con la comparecencia de Mnemósine. Las añejas vinculaciones entre la Retórica y la Historia, que de antiguo se materializaron en los teatros de la memoria y otros artilugios mnemotécnicos para que el orador no perdiera el hilo de su discurso, no dejaron de estar presentes en la fundación del código disciplinar. Y ello puede comprobarse incluso en el primerizo afán clasificatorio del conocimiento escolar, que, quizás siguiendo la estela taxonómica baconiana, pronto adjudicó a la Historia un lugar entre aquellas disciplinas que "requieren el auxilio de la memoria" (Gil de Zárate, I855, II, p. I9).

Los catedráticos decimonónicos de Geografía e Historia de los institutos, auténticas notabilidades de la cultura de provincias y "textos vivos" de la educación histórica, desempeńaron un protagonismo de primera magnitud en la elaboración de las piezas maestras del código disciplinar. Tanto con sus prácticas cotidianas como en la confección de textos visibles (son los principales autores de manuales escolares) esculpieron una tradición teórico-práctica que vivió en simbiosis con las reglamentaciones oficiales y con los contextos espacio-temporales en que se desenvolvió su vida profesional. En torno a ellos fue gestándose un ethos que cifraba el objetivo de la enseñanza de la Historia en la excelencia literaria y la declamación verbal. La transmisión oral desde la cátedra, el libro de texto como "auxilio de la memoria" y la repetición memorística en el duro trance examinatorio final constituían el somero itinerario pedagógico del curso escolar de Historia en la segunda enseñanza, que albergaba en sus aulas (cuyas formas arquitectónicas producían y acogían, a un tiempo, ese tipo de enseñanza) a los aspirantes a hacer del conocimiento histórico un complemento ostentoso de su futuro poder social.

Los cuerpos docentes encarnan así la tradición: crean y son creados a un tiempo por un mundo que los rebasa, porque "los "roles", como dirían Berger-Luckman (1993, p. 99), representan el orden institucional, de modo que el catedrático de Historia actúa 
qua catedrático, es decir, como individuo que es portador de valores y normas incrustadas en la vida cotidiana. En cierto modo, se diría que la construcción de la profesión es el resultado de lo que los actores representan y las imágenes de identidad y legitimidad proyectadas por la misma sociedad. De ahí la importancia del estudio de las "ideologías prácticas" y del habitus característicos de los cuerpos docentes como elementos decisivos en la configuración, reproducción y transmisión del código disciplinar de la Historia. $^{2}$

La propia práctica docente, pomposa y oratoria, ritualizada en el habitus profesional envuelve una concepción "aristocrática" de la cultura como derroche y disfrute restringido a unas determinadas clases sociales. El conocimiento histórico legítimo se contempla, dentro del campo profesional de los docentes, como una dato de la realidad, como una parte de la cultura "culta", no sometido a discusión, y, de esta manera, el proverbial y duradero desprecio hacia las modalidades de difusión masiva del conocimiento o de trasmutación pedagógica (su "pedagogización”) no son más que el reflejo de la cotización social de la Historia en un determinado contexto escolar y profesional. De modo que la conservación de una "Historia sin pedagogía", en el seno de las enseñanzas medias, vino a ser una salvaguardia de la función social atribuida a estos estudios, pero también una lacerante expresión de la ambivalencia esencial de los cuerpos docentes encargados de difundir y restringir, a un tiempo, el conocimiento histórico dentro de la circulación clasista del capital cultural que se opera en el seno del modo de educación tradicional-elitista.

El código disciplinar, una vez fundado, prolonga sus notas diferenciales en un vasto periodo histórico que llega hasta los años sesenta del siglo XX, momento en que empieza a cobrar fuerza en Espańa el nuevo modo de educación tecnocrático de masas. Ello no significa que, en ese extenso lapso, no acontezcan mutaciones en la educación histórica, ya que la dialéctica entre cambio y continuidad es inherente a cualquier tradición social; empero, en lo sustancial, los cuatro rasgos (arcaísmo, nacionalismo, elitismo y memorismo) con los que hemos reunido y resumido algunas de las claves del código disciplinar, subsisten junto a la diferenciación entre las "dos historias" escolares (con y sin pedagogía). Si bien es cierto que el juego de distancias y aproximaciones entre ambas propende a hacerse progresivamente más sutil y, al final, más liviano. Y ni que decir tiene que el efecto de los distintos regímenes políticos deja su huella en los usos de educación histórica: por ejemplo, desde principios de siglo XX, se consolida la presencia de la Historia escolar en todos los niveles educativos, se afianza la profesionalización historiográfica y se oyen voces, como la de Rafael Altamira, que reclaman una profunda transformación de la enseńanza de la Historia, mientras que el franquismo acentúa, hasta el disparate, las dimensiones más retrógradas del código disciplinar velando, que no sepultando del todo, los discursos y las prácticas más innovadoras. No obstante, el ritmo temporal del cambio no sigue las pautas de la sucesión de los regímenes políticos, porque los elementos del código disciplinar en tanto que componentes de una tradición social sobreviven, en gran medida, al devenir de las instancias político-institucionales y, en cambio, se ven más afectados y ceden más fácilmente ante las variaciones estructurales de otra naturaleza y de más extensa duración temporal. 


\section{La revisión discursiva del código disciplinar: con- tinuidades y cambios de la enseñanza de la Historia entre dos reformas (1970-1990)}

De lo anterior se deduce que el código disciplinar, una vez fundado a mediados del siglo XIX, no entra en una acelerada dinámica de cambio y reformulación hasta el desarrollo en Espańa del modo de educación tecnocrático de masas. Tal fenómeno comienza ya a esbozarse desde los ańos sesenta y acontece plenamente en el último tercio del siglo XX. Es entonces cuando, bajo los requerimientos socioculturales de una nueva educación de masas y la guía de una renovada y tecnicista racionalidad curricular, se procede a la realización de reformas de los sistemas educativos, que se extienden por todos los países de capitalismo tardío tras la Segunda Guerra Mundial. Estas reformas, que llegaron a España con un cierto retraso y no se abrieron camino hasta la Ley General de Educación de I970, no dejaron del todo incólume la "fortaleza inexpugnable" del currículo. En su mayor parte, las viejas disciplinas escolares han sobrevivido, pero la nueva razón tecnocrática y los modernos imperativos sociales de la educación de masas han erosionado algunas de sus pautas culturales y pedagógicas más tradicionales. La Historia no ha sido una excepción; el viejo cedazo que filtraba el conocimiento histórico impartido en las aulas ha sido cuestionado, llegándose a manifestar una cierta sospecha sobre el valor educativo de una disciplina que tradicionalmente había fundado su ser en la nacionalización del pasado y la retención memorista de sucesos encabalgados en un orden cronológico. Los debates corporativos y sociales acaecidos en varios países de nuestro entorno, que enarbolaron como estandarte y consigna la idea de "la Historia en peligro" (se supone que ante los excesos de las reformas educativas de los años sesenta y setenta), expresan una crisis de identidad, producto de una especie de duda ontológica sobre la Historia escolar, que, desde los ańos ochenta, parece estar resolviéndose mediante un atrincheramiento en posiciones cada vez más conservadoras y esencialistas. Es el triunfo de la disciplina (el orden del discurso disciplinar) frente a otras opciones más débiles (el orden del discurso psicopedagógico), lo que, siguiendo el marco analítico de Bernstein (1988) llamaríamos el retorno al "curriculum tipo colección" frente al "tipo integrado" y el consiguiente regreso a formas de "pedagogía visible". Tendencias que, en España, se expresan últimamente (nuevos programas obligatorios de enseñanzas mínimas de 200 y y actual Ley Orgánica de Calidad de la Educación) como una contrarreforma educativa neoliberal (frente al tinte más socialdemócrata de las políticas curriculares practicadas en España durante la década de los ochenta), promovida por la santa alianza de las fuerzas políticas conservadoras, los gremios de los historiadores profesionales (especialmente la Real Academia de la Historia) y más de un intelectual "humanista” despistado. Pero ¿qué sucedió, entre las dos reformas educativas, la de 1970 y la de 1990 , antes de que ocurriera el actual proceso de retorno hacia la Historia "de siempre"?

En Espańa , desde la Ley General de Educación, los cambios , acaecidos con cierto retraso respecto a otros países, se vieron, no obstante, amplificados y acelerados por la coyuntura de transformación socio-económica de los años sesenta y por las mutacio- 
nes socio-políticas ocurridas con motivo del tardofranquismo, el fin de la dictadura y la llamada transición democrática. De modo que al explorar la dinámica del cambio y la continuidad en la enseñanza de la Historia, entre 1970 y I990, se percibe, de inmediato, la importancia que ha adquirido la explosión cuantitativa de los agentes protagonistas de la educación histórica, auténtica "revolución silenciosa". En efecto, el crecimiento espectacular del número de alumnos en las enseńanzas medias (y especialmente de alumnas) rompe los moldes sociales de la enseńanza elitista del pasado, mientras que el correlativo aumento de los profesores (y sobre todo de profesoras) dedicados a la enseñanza de la Historia fractura de manera irreversible el armazón del campo profesional del vetusto y selecto cuerpo de catedráticos. Ahora, de este modo, la vieja corporación declina, víctima de un convergente proceso de "proletarización” y feminización, arrasando las identidades profesionales del pasado y sumiendo en un mar de dudas a los miles de profesores y profesoras que se ocupan de la enseñanza de las artes de Clío en los centros de educación secundaria.

En estas circunstancias, sucede como si la separación entre las "dos historias", con y sin pedagogía, empezara a rebajarse y diluirse. En efecto, si uno se fija en los textos visibles (programas y libros de texto) de la educación primaria y de las enseñanza medias, desde la Ley General de Educación (LGE) hasta la Ley de Ordenación del Sistema Educativo (LOGSE), se capta una nueva reciprocidad entre ambos: los primeros se "bachilleralizan" (se llenan de marcas y sobrentendidos propios de la "Historia sin pedagogía" de la tradicional educación secundaria) y los segundos se "egebeizan" (se pueblan de intenciones y seńales propias de la "Historia con pedagogía" de la primera enseñanza). Este juego de distancias y aproximaciones, apreciable sobre todo en la borrosa frontera y el inseguro territorio social existente entre las última fase de la Educación General Básica y primeros años del Bachillerato Unificado y Polivalente (lo que hoy se ha dado en llamar Educación Secundaria Obligatoria) deviene, así, en uno de los mecanismos que mejor pueden explicar los delicados matices del cambio y la continuidad en los usos de la educación histórica en la España del último tercio del siglo XX.

Para dar cuenta de la sutil y compleja trama de pervivencias y transformaciones del código disciplinar, acontecidas entre dos reformas educativas (la LGE de i970 y la LOGSE de 1990), he recurrido a una prospección analítica que hurga en tres capas o niveles de la Historia escolar: la Historia regulada (la que la Administración definió en sus programas y textos como conocimiento valioso), la Historia soñada (la que los grupos innovadores presentaron frente a la enseńanza tradicional) y la Historia enseñada (la que realmente se practicaba en las aulas). Pues bien, la primera y la segunda son las historias más proclives al cambio. La nueva racionalidad curricular se incorpora tempranamente (desde los ańos cincuenta se atisban ya en los cuestionarios algunos signos), y aunque los contenidos de los libros de texto permanecen más tiempo anclados en las fidelidades temáticas fascistas del régimen franquista, desde finales de los sesenta y comienzos de los setenta también allí se adivina una ruptura irreversible, que se plasma, ya en los ańos setenta, muy claramente tras la muerte de Franco, en un nítido distanciamiento del orden discursivo del tradicional nacionalismo españolista del código disciplinar y en un indudable remozamiento de las cuestiones historiográ- 
ficas, siguiendo, a cierta distancia, la estela de la renovación ocurrida en el mundo profesional de los historiadores.

Esta sensibilidad hacia la transformación se hace todavía más ostensible en los materiales didácticos y las actividades emprendidas por los grupos de renovación, que a partir de los ańos setenta retoman, sin demasiada conciencia de ello, el discurso de la Historia soñada iniciado desde finales del siglo XIX por obras como la de Rafael Altamira (1895). En una primera fase espontaneísta (1970-I983), los paradigmas dominantes fueron los grupos Rosa Sensat en primaria y Germanía en secundaria (las diferencias entre ellos expresan muy bien la supervivencia del trecho entre las dos historia escolares), que dentro de una rudimentaria e ingenua asimilación de teorías historiográficas (el marxismo, sobre todo a través de la obra de P. Vilar) y psicopedagógicas (desde la pedagogía por objetivos hasta las "aplicaciones" de Piaget, pasando por la pedagogía del entorno), mezcladas con un indisputable afán político de lucha por la democracia, fueron referentes modélicos e insoslayables de toda una época. Poco a poco, sin embargo, se observa una deriva de los discursos renovadores hacia el tecnicismo, que se hace más prominente cuando la Historia soñada (y una buena parte de sus más conspicuos representantes de la época anterior), en una segunda etapa (I983I995), se oficializa y cae en los brazos de un aparato tecnoburocrático al servicio de la reforma educativa emprendida de forma experimental en los ańos ochenta.

En la nueva Historia soñada se dieron cita "tres pistas" que hemos rastreado: la inglesa, representada por el proyecto History I3-I6 y las reflexiones epistemológicas de los defensores, como Hirst (I977) de un currículo disciplinar basado en "formas de conocimiento"; la psicológica, inicialmente alimentada sobre todo por los trabajos de los profesores Carretero, Pozo y Asensio, de la Univeridad Autónoma de Madrid; y la burocrática constituida por el elenco de asesores técnicos de las administraciones educativas que habían pasado de la investigación y el mundo de la renovación pedagógica al del diseño de los nuevos programas. Las tres pistas constituyen los nuevos saberespoderes de un renacido discurso disciplinar, supuestamente superador del ingenuismo pedagógico y la "ideologización" de la fase anterior. Coincidieron en defender, por distintas razones, el valor del conocimiento histórico, relegitimando su posición específica en el curriculum a base de endebles argumentos epistemológicos y psicológicos. Así, se creó y difundió una nueva doxa sobre la Historia y su enseñanza, sostenida y diseminada por las flamantes plataformas institucionales de investigación didáctica y las redes de formación del profesorado, que alcanzan ahora un notable desarrollo y un contorno cada vez más profesional-funcionarial. En paralelo a la oficialización del discurso renovador se va gestando, en el ámbito universitario, una corporación profesional que trata de "inventar" la didáctica de la historia y de las ciencias sociales como objeto de conocimiento, de suerte que en la última década se asiste al intento de institucionalización y codificación de un nuevo saber, cuyos principales creadores han tenido múltiples lazos con las pistas y los argumentos de la nueva Historia soñada.

Los representantes de la Historia soñada impugnaron reiteradamente, tanto en la fase espontaneísta como en la más oficializada e institucionalizada, la enseñanza tradicional de la Historia, propia del viejo código disciplinar inventado en el siglo XIX. Ello contribuyó, sin duda, a una crisis de legitimación de la Historia escolar, pero la 
razón crítica de la Historia soñada se erigió sobre fundamentos poco consistentes, ya que, en el fondo la nueva reclamación de la total autosufiencia de la disciplina como "forma de conocimiento" condujo a una doble ilusión, epistemológica y psicológica, en virtud de la cual se redujo, en buena medida, la Historia escolar al problema de las relaciones entre un saber científico específico ya hecho (la Historia) y las condiciones individuales que permiten su aprendizaje. De esta suerte, se ignoró la propia dimensión sociohistórica del conocimiento escolar y ello condujo a una inevitable reificación de la Historia; ahora el formalismo epistemológico, envuelto en el manto del reduccionismo psicologizante de raíz constructivista, impregnó la nueva doxa hegemónica en los espacios institucionales (despachos de la Administración educativa, departamentos universitarios, instituciones de formación de docentes), donde pugnaba por regenerarse el nuevo discurso de la Historia soñada.

Pero otros espacios eran, sin duda, las aulas, donde los cantos de sirena de la nueva Historia soñada, en sus dos etapas, fueron escasamente atendidos. Porque, en efecto, todo lo que podemos saber de la estancia de Clío en las aulas durante este tiempo, nos viene a asegurar que la Historia enseñada fue "otra" historia y que la diferencia entre lo que se regula y lo que se desea y "sueña" resulta muy pronunciada. El predominio de una enseñanza tradicional verbalista y memorista, con algunos matices no despreciables, parece, con todas las excepciones que se quiera, una evidencia incontrastable. En efecto, como si un tramposo e inquietante demiurgo moviera los hilos de los usos reales de la educación histórica, al mirar dentro de las aulas, nos topamos con una enseñanza muy al viejo estilo, que se encuentra muy lejos de las promesas, nunca cumplidas, de la Historia regulada y de la Historia soñada. Es aquí donde la perpetuación del código disciplinar se hace más tangible.

Los testimonios, observaciones e informes que traslucen la Historia enseñada registran, una y otra vez, la existencia de un profunda discrepancia entre lo que los profesores y profesoras de Historia dicen hacer y lo que hacen realmente en su vida docente cotidiana. Las rutinas que imperan y marcan el tic-tac cotidiano de la enseńanza de la Historia tienen que ver con las características de la escuela como espacio de socialización, en el que las funciones explícitas de distribución del conocimiento se ocultan tras otras más escondidas y determinantes. En el marco de las formas escolares de socialización del capitalismo tardío, la vida en las aulas transcurre bajo los complejos, poderosos y no siempre visibles designios de las constricciones espacio-temporales, el habitus de la función de profesor y el peso abrumador de una tradición sociocultural adherida como una piel al cuerpo de la institución escolar. Los trabajos más recientes, como la tesis doctorales de J. Romero (200I) y de J. Merchán (200I), vienen a fortalecer estas ideas.

En resumen, las transformaciones en la enseñanza de la Historia en el modo de educación tecnocrático de masas han existido, especialmente a partir de los años setenta. El más que centenario código disciplinar ha resultado impugnado en sus dimensiones más declarativas y visibles, y en los propios programas de la educación histórica. Los discursos renovadores de la Historia soñada, haciendo uso de viejas y nuevas ilusiones epistemológicas y psicológicas, han puesto, una y otra vez, en entredicho la enseñanza tradicional de la Historia. Sin embargo, asomándonos al interior de la aulas, el cono- 
cimiento histórico que se divisa no concuerda con el regulado y el sońado. El vetusto código disciplinar ha sido puesto en solfa, deslegitimado y erosionado mucho más en el ámbito de lo enunciativo que en el de los usos reales de la educación histórica. Así pues, en las prácticas discursivas predominan las ilusiones de diversa estirpe, desprovistas de fundamento sólido; en las aulas, se dan cita las rutinas. No obstante, las últimas medidas educativas contrarreformistas parecen ir encaminadas hacia una imposible resurección del viejo código disciplinar de la historia escolar. Malos tiempos corren, en verdad, para el ejercicio de una didáctica crítica de la de la Historia.

\section{Notas}

I. La reconstrucción de una genealogía de las disciplinas escolares en España está lejos de haberse concluído. Tras el trabajo pionero de A. Luis (1985), son ya abundantes los estudios realizados, aunque a menudo inscritos en una concepción narrativista, evolucionista y teleológica de la historia del curriculum. Mi aportación rompe con ese enfoque, tal como puede consultarse, con más detalle, en mis libros (Cuesta, I997 y 1998), que desarrollan lo que en este artículo sólo se esboza.

2. Todavía está pendiente la tarea de reunir la mirada sociológica e histórica en un mismo planteamiento metodológico. Eso he pretendido con el uso de categorías como habitus (Bourdieu, 1997) o "ideologías prácticas" (Giddens, 1995). En el fondo, una historia social de la educación necesita de una teoría de la acción y del sujeto como la que ha venido defendiendo P. Bourdieu en sus escritos.

\section{Referencias}

Altamira, R. (1895). La enseñanza de la Historia. Madrid: Victoriano Suárez .

Berger, P., \& Luckman, Th. (1993). La construcción social de la realidad. Buenos Aires: Amorrortu.

Bernstein, B. (1988). Clases, códigos y control. II. Hacia una teoría de las transmisiones educativas. Madrid: Akal.

Boyd, C. P. (1997). Historia patria. Politics, History and National Identity in Spain, I875-1975. Princeton, NJ: Princenton University Press.

Bruter, A. (1997). L 'Histoire enseignée au Grand Siècle. Naissance d'une pédagogie. Paris: Belin.

Bourdieu, P. (1997). Razones prácticas. Sobre la teoría de la acción. Barcelona: Anagrama.

Carretero, M., Pozo, J. I., \& Asensio, M. (Eds.). (1989). La enseñanza de las ciencias sociales. Madrid: Visor.

Chervel, A. (199I). Historia de las disciplinas escolares. reflexiones sobre un campo de investigación. Revista de Educación, 295, 59-III.

Citron, S. (1989). Le mythe national. L' histoire de France en question. Paris: Les Editions Ouvrières.

Cuesta, R. (1997). Sociogénesis de una disciplina escolar: la Historia. Barcelona: PomaresCorredor.

Cuesta, R. (1998). Clío en las aulas. La enseñanza de la Historia en España entre reformas, ilusiones y rutinas. Madrid: Ediciones Akal.

Duchesne, J. B. (176I). Compendio de Historia de España, escrito por el R. P. Duchesne, de la Compañía de Jesús, Maestro de sus Altezas Reales los Señores Infantes de España. Traducido, e ilustrado con notas críticas por el R.P. Joseph Francisco de Isla de las misma Compañía, dedicóse al Excmo. Señor D. Bernardo O’Connor, señor de Ofalia. Pamplona: Oficina de los Herederos de Martínez.

Durkheim, E. (1982). Historia de la educación y de las doctrinas pedagógicas. La evolución pedagógica en Francia. Madrid: La Piqueta. 
Foucault, M. (1992). "Memoria redactada para la candidatura al Collège de France. En D. Eribon, Michel Foucault (pp. 423-428). Barcelona: Anagrama.

García Puchol, J. (1993). Los textos escolares de Historia en la enseñanza española (I808-1900). Análisis de su estructura y contenido. Barcelona: Publicaciones de la Universidad de Barcelona.

Giddens, A. (1995). La constitución de la sociedad. Bases para la teoría de la estructuración. Buenos Aires: Amorrortu.

Gil de Zárate, A. (I855). De la Instrucción pública en España. 3 vols., Madrid: Imprenta del Colegio de Sordomudos.

Goodson, I. F. (1995). Historia del currículum. La construcción social de las disciplinas escolares. Barcelona: Pomares-Corredor.

Hirst, P. H. (1977). La educación liberal y la naturaleza del conocimiento. En R. S. Peters (comp.), Filosofía de la educación (pp. I6I-205). México: F.C.E.

Lerena, C. (1976). Escuela, ideología y clases sociales en España. Barcelona: Ariel.

López Facal, R. (1995). O concepto de nación no ensino da Historia. Tesis doctoral inédita. Santiago de Compostela: Universidad de Santiago.

Luis Gómez, A. (1985). La geografía en el Bachillerato español. Barcelona: Publicaciones de la Universidad de Barcelona.

Merchán, J. (200I). La producción del conocimiento escolar en la clase de historia: profesores, alumnos y prácticas pedagógicas en la Educación Secundaria. Tesis doctoral inédita. Sevilla: Universidad de Sevilla.

Pozo Andrés, Ma . M. (200o). Curriculum e identidad nacional. Madrid: Biblioteca Nueva.

Romero, J. (200I). La clase artificial. Recursos informáticos y educación histórica. Madrid: Akal.

Rivera, J. F. (1847). Curso elemental de Historia, arreglado al programa de ${ }^{\circ}$ de Agosto de 1846 adornado con tres cuadros sinópticos y tablas cronológicas que facilitan su estudio. 2 vols., Valladolid: Imprenta de D. M. Aparicio.

Sánchez Casado, F. (1873). Historia Universal para uso de los alumnos de los Institutos, colegiosy seminarios. Madrid: Imprenta a cargo de Gregorio Juste.

Terradillos, A. M. (1846). Prontuario de Historia de España. Madrid: Imprenta Jordán e Hijos. Verdejo Páez, F. (1846). Elementos de Historia Universal. Madrid: Imprenta de D. José Repullés. 
42 Encounters/Encuentros/Rencontres 